\title{
The efficacy and adverse reactions of DCF and FOLFOXs regimens for patients with advanced gastric cancer in China: a meta-analysis
}

\author{
Minxue Chen ${ }^{1 \#}$, Yong Fan ${ }^{1 \#}$, Zhiqiang Zhao ${ }^{1}$, Yuanhua Nie ${ }^{1}$, Fulin $\mathrm{Ma}^{1}$, Xingang Wang ${ }^{1}$, Qiuya Wei ${ }^{1}$, \\ Yuebin Wang ${ }^{1}$, Boxiong Kang ${ }^{1}$, Yongyong Liu ${ }^{1}$, Hao Chen ${ }^{2}$, Chen Wang ${ }^{1}$ \\ ${ }^{1}$ Department of Minimally Invasive Surgery, ${ }^{2}$ Department of Oncology Surgery, The Second Hospital of Lanzhou University, Lanzhou, China \\ Contributions: (I) Conception and design: M Chen, Y Fan, C Wang; (II) Administrative support: Z Zhao, Y Nie, F Ma, X Wang, Q Wei, Y Wang, \\ B Kang, Y Liu, H Chen; (III) Provision of study materials or patients: Y Nie, F Ma; (IV) Collection and assembly of data: Z Zhao, Y Nie, F Ma, X \\ Wang, Q Wei; (V) Data analysis and interpretation: M Chen, Y Fan; (VI) Manuscript writing: All authors; (VII) Final approval of manuscript: All \\ authors. \\ "These authors contributed equally to this work. \\ Correspondence to: Chen Wang. The Second Hospital of Lanzhou University, No. 82 Cuiying Gate, Chengguan District, Lanzhou 730000 , China. \\ Email: chenwang303@sina.com.
}

\begin{abstract}
Background: Gastric cancer is a malignant tumor originating from the gastric mucosal epithelium, ranking fourth in the incidence of male malignant tumors and third in mortality rate. The aim of this study is to investigate the efficacy and adverse reactions of DCF and FOLFOXs regimens in the treatment of advanced gastric cancer.

Methods: Relevant prospective clinical controlled studies were retrieved from WanFang Data, CBM, CNKI, PubMed, The Cochrane Library and Embase databases and meta-analysis was performed using RevMan 5.3 software.

Results: The effective rates of DCF group and FOLFOXs group were basically the same (RR 1.06, 95\% CI: $0.92-1.23, \mathrm{P}=0.41)$. The incidence of nausea and vomiting (RR 1.36, 95\% CI: 1.15-1.60), anemia (RR 2.04, 95\% CI: 1.55-2.68), thrombocytopenia (RR 1.52, 95\% CI: 1.15-2.01) and leukopenia (RR 1.70, 95\% CI: 1.44-2.01) with FOLFOXs regimen were significantly lower than DCF regimen, while the incidence of sensory neurotoxicity was significantly higher than DCF regimen (RR 0.53, 95\% CI: 0.38-0.74). There were no significant differences in efficacy, ORR and DCR between different doses in the FOLFOXs group $(\mathrm{P}=0.233)$.

Conclusions: The efficacy of FOLFOXs regimen was comparable to that of DCF regimen in the treatment of advanced gastric cancer, but the incidence of adverse reactions was significantly lower, and there were no significant differences between different therapeutic doses.
\end{abstract}

Keywords: Advanced gastric cancer; DCF regimen; FOLFOXs regimen; efficacy; adverse reactions

Submitted Nov 21, 2019. Accepted for publication May 29, 2020.

doi: $10.21037 /$ tcr-19-2564

View this article at: http://dx.doi.org/10.21037/tcr-19-2564

\section{Introduction}

Gastric cancer is a malignant tumor originating from the gastric mucosal epithelium, ranking fourth in the incidence of male malignant tumors and third in mortality rate, and seventh in the incidence of female malignant tumors and fifth in mortality rate (1), imposing serious damages to the people's health. Early gastric cancer often manifests as upper abdominal discomfort, non-specific symptoms such as fullness and nausea after eating, and it is difficult to differentiate early from other gastric diseases. Some 
Table 1 PubMed search strategy

\begin{tabular}{lc}
\hline Steps & Search strategy \\
\hline$\# 1$ & Docetaxel \\
$\# 2$ & Cisplatin \\
$\# 3$ & Fluorouracil \\
$\# 4$ & $\# 1$ OR \#2 OR \#3 \\
$\# 5$ & Oxaliplatin \\
$\# 6$ & Fluorouracil \\
$\# 7$ & Leucovorin \\
$\# 8$ & \#4 OR \#5 OR\#6 \\
$\# 9$ & Advanced gastric cancer \\
$\# 10$ & \#4 AND \#8 AND \#10 \\
\hline
\end{tabular}

patients with gastric cancer have progressed to advanced stage and are difficult to undergo radical resection. DCF regimen [docetaxel (TXT) + cisplatin (DDP) + fluorouracil (FU)] and FOLFOXs regimen [oxaliplatin (L-OHP) + fluorouracil $(\mathrm{FU})+$ leucovorin $(\mathrm{LV})$ ] are the currently used chemotherapy for gastric cancer. However, due to its many adverse reactions and uncertainties in efficacy, selecting an appropriate chemotherapy regimen is another important issue in our clinical work. Therefore, this study intends to conduct a meta-analysis of the efficacy and adverse effects of DCF and FOLFOXs regimens in patients with advanced gastric cancer, and systematically evaluate the clinical value of the two chemotherapy regimens from the perspective of evidence-based medicine. We present the following article in accordance with the PRISMA reporting checklist (available at http://dx.doi.org/10.21037/tcr-19-2564).

\section{Methods}

\section{Search strategy}

WanFang Data, CNKI, PubMed, The Cochrane Library, Embase databases were retrieved using computer according to the "PICOS" search principle, combined keywords and free words for related documents published since the establishment of the databases. The Chinese search terms were: “晚期胃癌” “奥沙利铂” “顺铂” “多西他赛” “亚叶酸 钙” “氟尿嘧啶”. The English search terms were: “advanced gastric cancer" "Oxaliplatin" "Cisplatin" "Docetaxel" "Leucovorin" "Fluorouracil". At the same time, the references of the articles included and related meta-analysis were traced. Take PubMed as an example, the specific search strategy was as shown in Table 1.

\section{Study inclusion and exclusion}

Type of study: randomized controlled study.

Inclusion criteria: (I) pathological diagnosis of advanced gastric cancer; (II) KPS score $\geq 60$ points; (III) imaging and laboratory tests showed that the heart, liver, kidney and hematopoietic function were basically normal, and the expected survival time $>3$ months.

Exclusion criteria: (I) old literature; (II) incomplete data due to loss of follow-up or other reasons (and not stated in the text); (III) similar or identical repeated reports; (IV) single-center repeated studies; (IV) single protocol sample size $\mathrm{n}<20$; (VI) combined with other treatments (add other chemotherapy or radiotherapy).

The basic characteristics of the experimental group and control group were comparable.

Outcome indicators: (I) chemotherapy efficacy (using Response Evaluation Criteria in Solid Tumors (RECIST) to evaluate the efficacy of tumor chemotherapy); (II) adverse reactions such as anemia, leukopenia, thrombocytopenia, nausea and vomiting.

\section{Literature screening}

Two evaluators independently selected the literature according to the pre-determined inclusion criteria, first read the literature title and abstracts, followed by the full text of the literature for those that might meet the inclusion criteria, to determine whether it met the inclusion criteria. After cross checking the results, the data of research that met the requirements were extracted in the Excel data extraction table, and in case of disagreement, it is solved through discussion with a third party.

\section{Literature quality evaluation}

The Cochrane Handbook for RCT bias risk assessment tools was used to evaluate the literature including random sequence generation, allocation concealment, participant and investigator blinding, assessor blinding, outcome indicator integrity, selective reporting, and other sources of bias. Each item was rated as "low risk of bias" "unclear" and "high risk of bias" according to the evaluation criteria. 


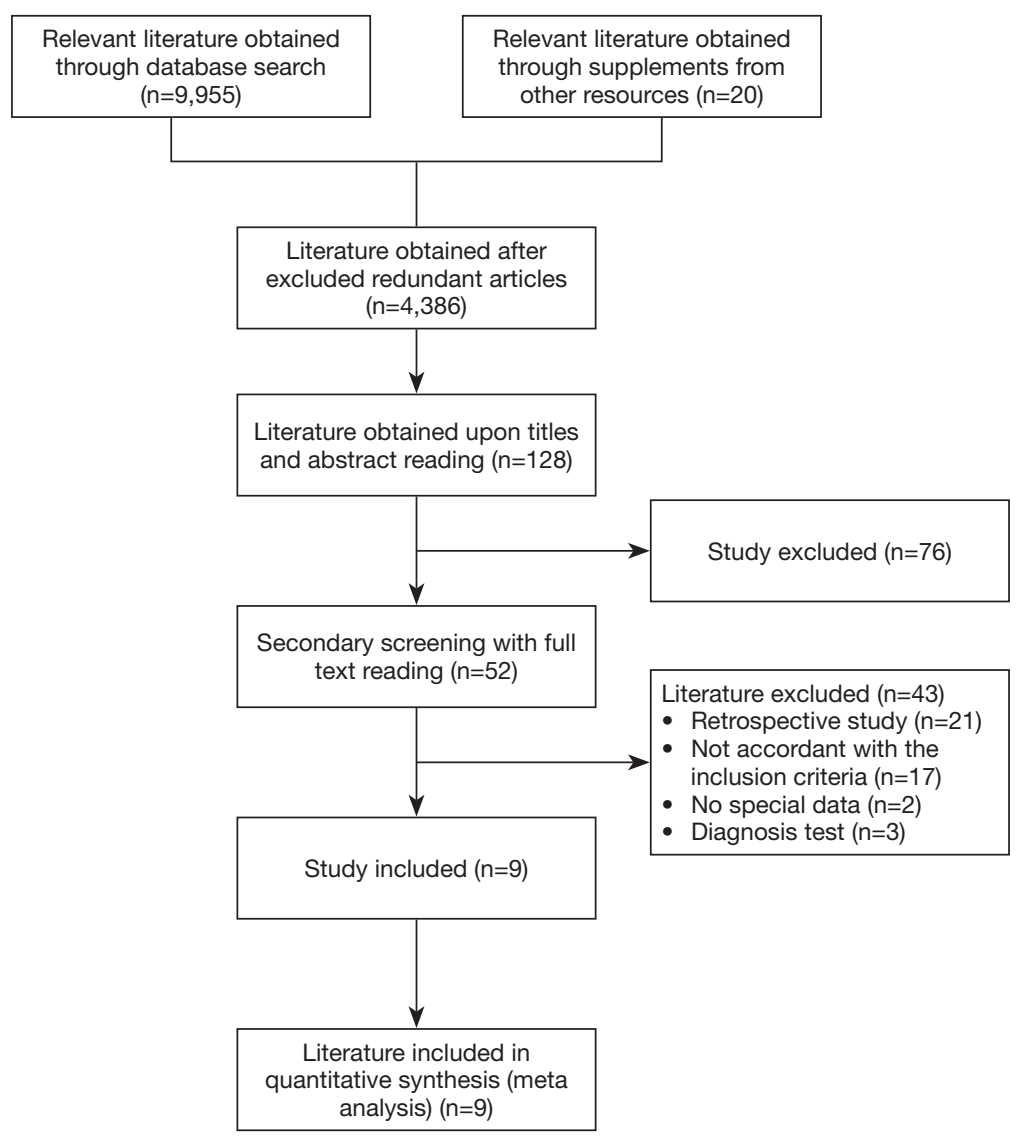

Figure 1 Flow chart of study for identification, inclusion, and exclusion. The number of specific search databases and literature: PubMed $(\mathrm{n}=3,219)$, The Cochrane Library $(\mathrm{n}=537)$, CNKI $(\mathrm{n}=1,064)$, Embase $(\mathrm{n}=3,325)$, Wanfang data $(\mathrm{n}=1,198)$, CBM $(\mathrm{n}=710)$.

\section{Data statistics indicators and analysis methods}

RECIST was used to describe changes in tumors after chemotherapy, including: complete response (CR), partial response (PR), disease stable (no change, $\mathrm{NC}$ ) and progressive disease $(\mathrm{PD})$ in all articles included objective response rate (ORR) and disease control rate (DCR). Data statistics were analyzed using Review Manager 5.3 software, with relative risk (RR) as analytical statistic for the counting data, and 95\% confidence interval (CI) for each effect quantity. Before data analysis, $\chi^{2}$ test was used to test for heterogeneity. If $\mathrm{P}>0.05, \mathrm{I}^{2} \leq 50 \%$, fixed effect model was used for analysis. Otherwise, random effect model was used. The final result was presented in the form of forest map, and $\mathrm{P}<0.05$ was considered to be statistically significant. Publication bias was evaluated by funnel plot.

\section{Results}

\section{Document search process and results}

A total of 52 Chinese literatures were initially screened. After reviewing the full text, 9 articles were obtained according to the inclusion and exclusion criteria of the study. A total of 715 patients were enrolled, including 360 in the DCF group and 355 in the FOLFOXs group. The flow chart or study was as shown in Figure 1.

\section{Basic information of the included studies and quality evaluation}

The basic characteristics of the literature of the included studies were shown in Table 2. There was a total of 9 RCTs, 
Table 2 Basic characteristics and methodological quality evaluation of the included studies

\begin{tabular}{|c|c|c|c|c|c|c|c|c|c|c|c|c|c|c|}
\hline \multirow{3}{*}{ Included studies } & \multirow{3}{*}{ Case collection period } & \multirow{3}{*}{$\begin{array}{l}\text { Grouping } \\
\text { method }\end{array}$} & \multicolumn{2}{|c|}{ Research object of DCF regime } & \multicolumn{2}{|c|}{ Research object of FOLFOXs regime } & \multirow{3}{*}{$\begin{array}{l}\text { Observation } \\
\text { indicator }\end{array}$} & \multicolumn{7}{|c|}{ Methodology quality evaluation } \\
\hline & & & \multirow{2}{*}{$\begin{array}{c}\text { Gender } \\
\text { (male/female) }\end{array}$} & \multirow[b]{2}{*}{ Age (year) } & \multirow{2}{*}{$\begin{array}{c}\text { Gender } \\
\text { (male/female) }\end{array}$} & \multirow[b]{2}{*}{ Age (year) } & & \multirow[b]{2}{*}{ Random method } & \multirow[b]{2}{*}{ Allocation concealment } & \multirow{2}{*}{$\begin{array}{l}\text { Completeness of the } \\
\text { outcome data }\end{array}$} & \multirow{2}{*}{$\begin{array}{l}\text { Selective reporting } \\
\text { of the research } \\
\text { findings }\end{array}$} & \multicolumn{2}{|c|}{ Blind method } & \multirow{2}{*}{$\begin{array}{l}\text { Other sources } \\
\text { of bias }\end{array}$} \\
\hline & & & & & & & & & & & & $\begin{array}{l}\text { Patients and } \\
\text { investigator }\end{array}$ & $\begin{array}{l}\text { Outcome } \\
\text { assessor }\end{array}$ & \\
\hline Zhikuan Wang, 2009 (2) & 2006.1 to 2008.12 & RCT & $32 / 12$ & $55.78 \pm 10.24$ & $30 / 12$ & $55.78 \pm 10.24$ & (1)(2) & $\begin{array}{l}\text { Computer random } \\
\text { selection }\end{array}$ & Sealed envelope & Complete & No & No & Unclear & Unclear \\
\hline Meiqing Luo, 2011 (3) & 2004.1 to 2008.4 & $\mathrm{RCT}$ & $26 / 9$ & $57.3 \pm 8.1$ & $26 / 8$ & $57.3 \pm 8.3$ & (1)(2) (3) & Unclear & Unclear & Complete & No & No & Unclear & Unclear \\
\hline Guohua Han, 2011 (4) & 2004.3 to 2010.3 & RCT & $20 / 8$ & $50.3 \pm 4.2$ & $19 / 9$ & $50.3 \pm 4.1$ & (1)(2)(4) & Unclear & Unclear & Complete & No & No & Unclear & Unclear \\
\hline Lu Bai, 2012 (5) & 2008.7 to 2011.6 & RCT & $17 / 16$ & $57.35 \pm 10.52$ & $18 / 15$ & $57.35 \pm 10.52$ & (1)(2) (5) & $\begin{array}{l}\text { Computer random } \\
\text { selection }\end{array}$ & Sealed envelope & Complete & No & No & Unclear & Unclear \\
\hline Huiqiong Sun, 2016 (6) & 2010.1 to 2016.1 & RCT & $37 / 29$ & $57.39 \pm 10.55$ & $36 / 30$ & $57.36 \pm 10.53$ & (1)(2) (5) & $\begin{array}{l}\text { Computer random } \\
\text { selection }\end{array}$ & Sealed envelope & Complete & No & No & Unclear & Unclear \\
\hline Lihua Fang, 2017 (7) & 2015.9 to 2016.12 & RCT & 19/11 & $56.2 \pm 4.2$ & $18 / 12$ & $57.5 \pm 4.1$ & (1)(2)(6) & $\begin{array}{l}\text { Computer random } \\
\text { selection }\end{array}$ & Sealed envelope & Complete & No & No & Unclear & Unclear \\
\hline Jianhuang Li, 2009 (8) & 2005.1 to 2008.1 & RCT & $32 / 20$ & $55.7 \pm 4.7$ & $31 / 21$ & $55.7 \pm 4.5$ & (1)(2) (5) & Unclear & Unclear & Complete & No & No & Unclear & Unclear \\
\hline Xiaohui Yang, 2012 (9) & 2007.1 to 2008.6 & RCT & $22 / 10$ & $50.2 \pm 4.2$ & 19/11 & $50.2 \pm 4.2$ & (1)(2) (6) (7) & $\begin{array}{l}\text { Computer random } \\
\text { selection }\end{array}$ & Sealed envelope & Complete & No & No & Unclear & Unclear \\
\hline Defu Wu, 2016 (10) & 2010.5 to 2015.6 & $\mathrm{RCT}$ & $26 / 14$ & $58.3 \pm 9.1$ & $25 / 15$ & $58.1 \pm 9,2$ & (1)(2) (5) & $\begin{array}{l}\text { Computer random } \\
\text { selection }\end{array}$ & Sealed envelope & Complete & No & No & Unclear & Unclear \\
\hline
\end{tabular}



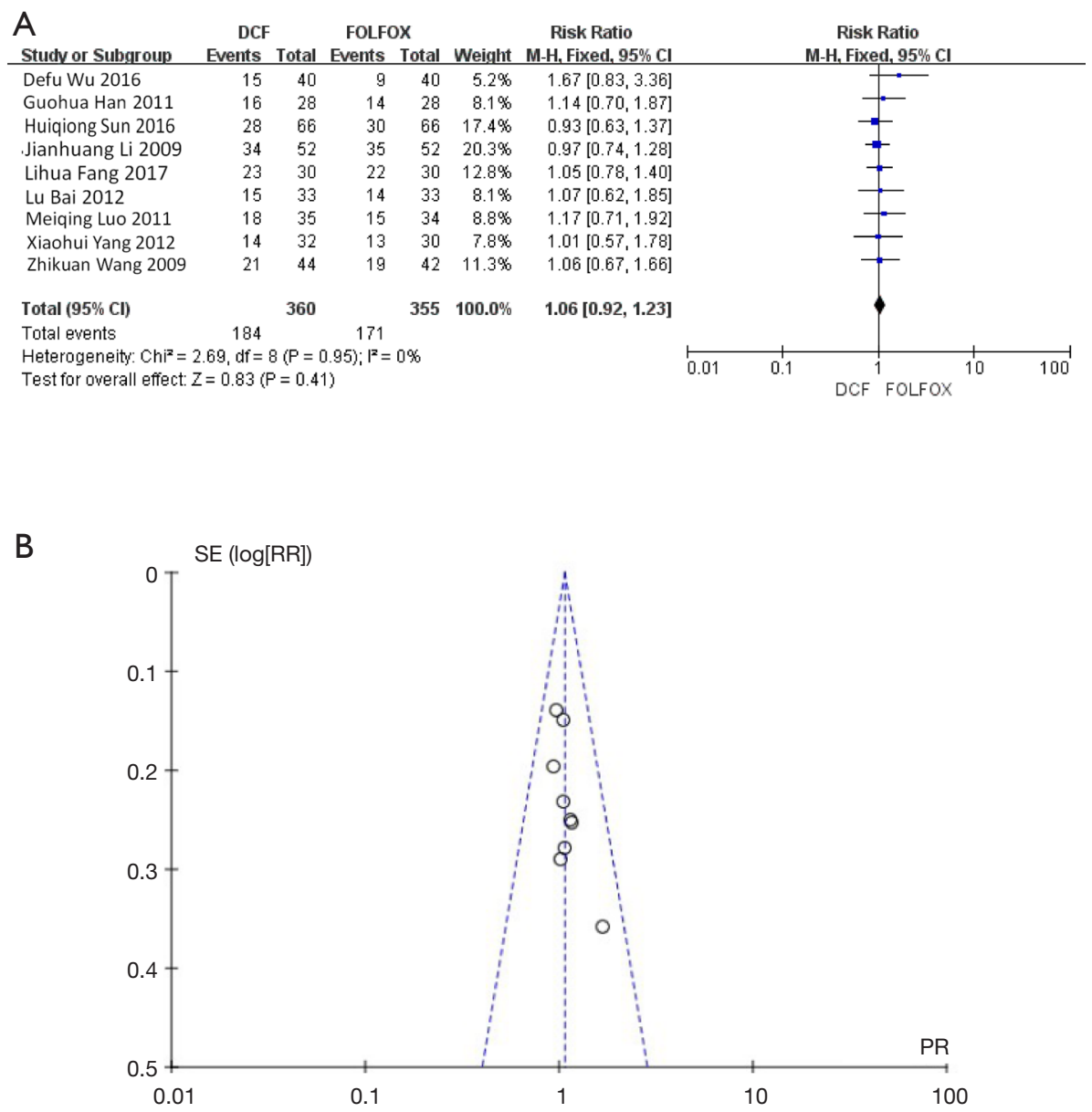

Figure 2 The effective rate of chemotherapy DCF and FOLFOXs regimens in patients with advanced gastric cancer. (A) Forest chart. The response rate of chemotherapy of the included studies was calculated by CR + PR; (B) The publication bias was shown in funnel plot. DCF, docetaxel (TXT) + cisplatin (DDP) + fluorouracil (FU); FOLFOXs, oxaliplatin (L-OHP) + fluorouracil (FU) + Leucovorin (LV); CR, complete response; $\mathrm{PR}$, partial response.

all of which were multicenter clinical studies. Age, gender and other data were described in detail in each study, and there were no significant differences between the two treatment regimens $(\mathrm{P}>0.05)$.

\section{Efficacy of the two chemotherapy regimens}

The response rate of chemotherapy of the included studies was calculated by CR + PR. The heterogeneity of the included studies was $\mathrm{P}=0.95, \mathrm{I}^{2}=0 \%$, thus fixed effect model was used. Statistical analysis by Review Manager 5.3 software the effective rates of DCF group and FOLFOX group were $51.11 \%$ and $48.17 \%$, respectively (RR 1.06 , 95\% CI: $0.92-1.23)$. There was no statistical significance between the two groups $(\mathrm{P}=0.41)$, as shown in Figure $2 A$.
Then we analyzed the publication bias. The small sample studies were distributed at the bottom of the funnel plot, while large sample studies were distributed at the top of the funnel plot, and basically arranged symmetrically around the center baseline, suggesting that publication bias of the literature of the included studies was relatively small, as shown in Figure $2 B$.

\section{ORR and DCR of the two chemotherapy regimens}

The ORR and DCR of the DCF and FOLFOXs regimens were evaluated. All ORR evaluation showed no significant differences between the DCF and FOLFOXs regimens (RR 1.06, 95\% CI: 0.92-1.23; $\mathrm{P}=0.41$ ) (Figure 3A). All DCR evaluation showed no significant differences between the 


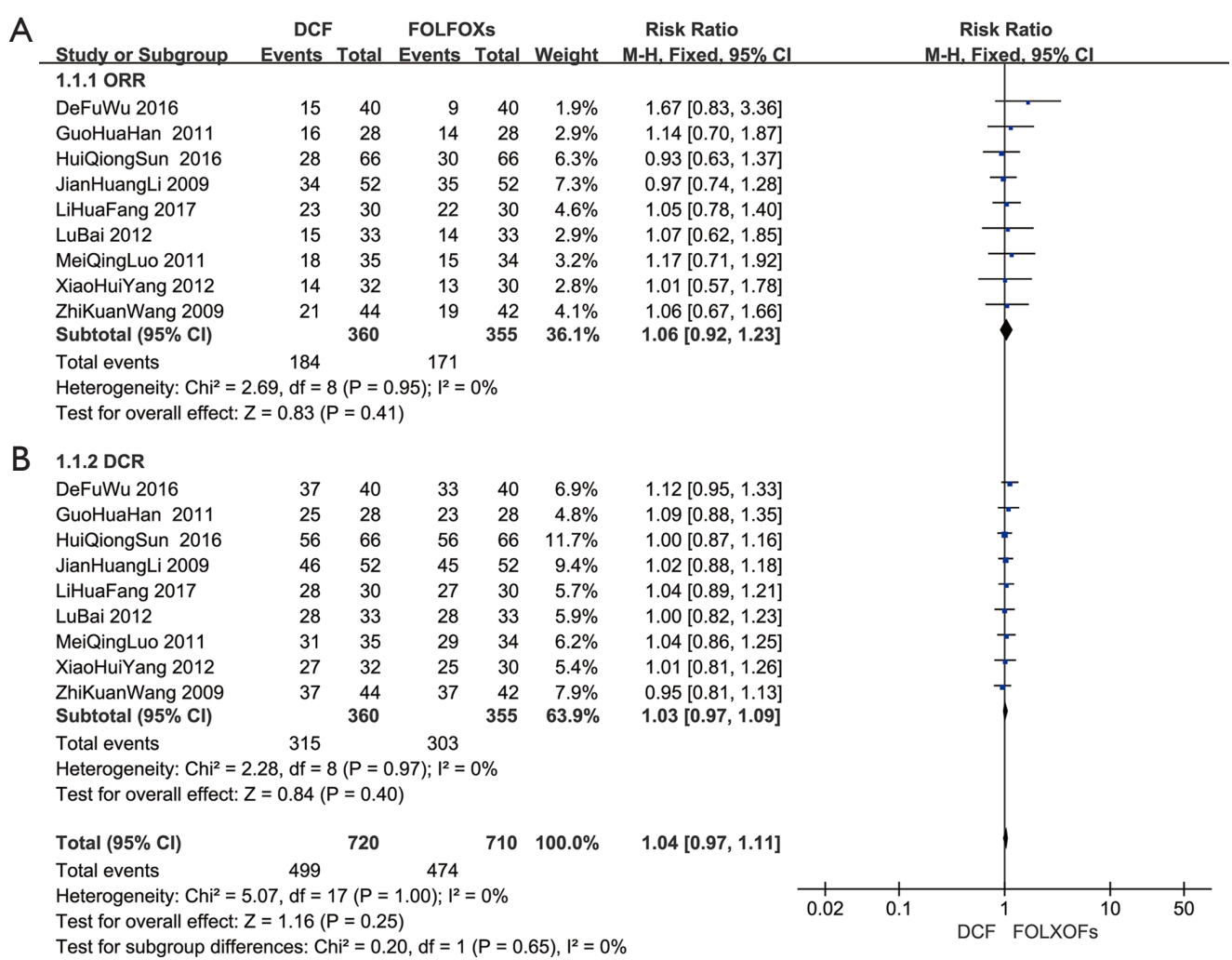

Figure 3 ORR and DCR of the two chemotherapy regimens. (A) ORR evaluation showed no significant differences between the DCF and FOLFOXs regimens. (B) DCR evaluation showed no significant differences between the DCF and FOLFOXs regimens. ORR, objective response rate; DCR, disease control rate.

DCF and FOLFOXs regimens (RR 1.03, 95\% CI: $0.97-$ 1.09; $\mathrm{P}=0.40$ ) (Figure 3B).

\section{Adverse reactions of the two chemotherapy regimens}

The types of adverse reactions in the DCF regimen and the FOLFOXs regimen were statistically analyzed and the results were shown in Table 3. The common adverse reactions of DCF regimen and FOLFOXs regimen were mainly found in the blood system (anemia, leukopenia and thrombocytopenia), digestive system (diarrhea, nausea and vomiting), and other systems (oral mucositis, sensory neurotoxicity and hepatic insufficiency). Statistical analysis was performed using Review Manager 5.3 software. The results showed that the incidence of nausea and vomiting (RR 1.36, 95\% CI: 1.15-1.60), anemia (RR 2.04, 95\% CI: 1.55-2.68), thrombocytopenia (RR 1.52, 95\% CI: $1.15-2.01$ ) and leukopenia (RR 1.70, 95\% CI: 1.44-2.01) of the FOLFOXs regimen was significantly lower $(\mathrm{P}<0.05)$, while the incidence of sensory neurotoxicity (RR 0.53, 95\% CI: 0.38-0.74) was significantly higher $(\mathrm{P}=0.0002)$ in the FOLFOXs regimen than the DCF regimen (Table 3, Figure 4).

\section{Analysis of the efficacy and adverse reactions of different cumulative therapeutic doses in the FOLFOXs regimen}

The 7 included studies were grouped according to the cumulative therapeutic doses of FOLFOXs regimen, which were mainly divided into FOLFOX4 regimen group and FOLFOX6 regimen group (group III). FOLFOX4 regimen group can be divided into groups I and II according to the doses of fluorouracil used (Table 4). The differences in efficacy and adverse effects of each cumulative therapeutic dose in the FOLFOXs regimens were analyzed. There were no significant differences in efficacy between the three groups $(\mathrm{P}=0.233)$. Analysis of the adverse reactions showed no significant differences in the incidence of diarrhea, hepatorenal dysfunction, and oral mucositis between the groups. 
Table 3 Statistical table of chemotherapy adverse reactions in patients with advanced gastric cancer with DCF and FOLFOXs

\begin{tabular}{|c|c|c|c|c|c|c|c|c|c|}
\hline Adverse reactions & $\begin{array}{c}\text { Numbers of } \\
\text { included studies }\end{array}$ & $\begin{array}{l}\text { DCF group } \\
(\mathrm{n} / \mathrm{N})\end{array}$ & $\begin{array}{l}\text { FOLFOXs } \\
\text { group }(n / N)\end{array}$ & \multicolumn{2}{|c|}{ Heterogeneity } & $\mathrm{RR}$ & $95 \% \mathrm{Cl}$ & \multicolumn{2}{|c|}{ Test for overall effect } \\
\hline Anemia & $5(3-6,8)$ & $94 / 214$ & $46 / 213$ & 0 & 0.90 & 2.04 & $1.55-2.68$ & 5.05 & $<0.00001$ \\
\hline Leukopenia & $7(3-6,8-10)$ & $172 / 286$ & $100 / 283$ & 51 & 0.06 & 1.70 & $1.44-2.01$ & 6.19 & $<0.00001$ \\
\hline Thrombocytopenia & $6(3-6,8,9)$ & $85 / 246$ & $55 / 243$ & 83 & $<0.0001$ & 1.52 & $1.15-2.01$ & 2.90 & 0.004 \\
\hline Nausea and vomiting & $5(3-5,8,10)$ & $132 / 188$ & $97 / 187$ & 51 & 0.09 & 1.36 & $1.15-1.60$ & 3.61 & 0.0003 \\
\hline Hepatic insufficiency & $3(3,5,9)$ & $26 / 100$ & $23 / 97$ & 19 & 0.29 & 1.08 & $0.69-1.67$ & 0.32 & 0.75 \\
\hline Peripheral neurotoxicity & $6(3-5,8-10)$ & $41 / 220$ & $76 / 217$ & 74 & 0.002 & 0.53 & $0,38-0.74$ & 3.72 & 0.0002 \\
\hline Oral mucositis & $2(3,5)$ & $13 / 68$ & $11 / 67$ & 0 & 0.87 & 1.17 & $0.57-2.39$ & 0.44 & 0.66 \\
\hline
\end{tabular}

\section{Discussion}

Gastric cancer is the fifth largest cancer in the world. Clinical research shows that surgical treatment, such as expanded regional lymph node dissection and combined with multiple organ resection, cannot bring more survival benefits to patients with advanced gastric cancer (11). Therefore, chemotherapy is essential to improve the quality of life of patients with advanced gastric cancer, but there is no "gold standard" for the selection of chemotherapy regimen in the world. At the same time, with more in depth into "individualized treatment" and "targeted therapy", higher requirements were proposed for selection of chemotherapy regimens for advanced gastric cancer (12).

From neoadjuvant chemotherapy to adjuvant chemotherapy, there are numerous chemotherapy regimens for gastric cancer. Currently, for palliative chemotherapy for advanced gastric cancer, the treatment option for firstline chemotherapy is still fluorouracil (5-Fu, Tegafur, Capecitabine) (13-17), platinum-based (cisplatin, oxaliplatin) (18), taxanes (Docétaxel, Paclitaxel) (19), Epirubicin (20) and Irinotecan (20,21). Although there are support from multiple clinical studies, the most commonly used adjuvant therapy is XELOX and SOX (22-24), but its efficacy and adverse effects with DCF and FOLFOXs regimens are still controversial (25-27), and there is no meta-analysis of big data to indicate the clinical advantages and disadvantages between them. Therefore, the DCF and FOLFOX regimens, as the classic treatment of advanced gastric cancer, still have their unique clinical application value. At present, there is no meta-analysis to indicate the efficacy and adverse reactions of DCF and FOLFOXs regimens in the treatment of advanced gastric cancer. In this study, we collected the local research literature on the treatment of advanced gastric cancer with DCF and FOLFOXs regimens in recent years, and compared their efficacy and adverse reactions.

\section{Efficacy analysis}

Hacibekiroglu et al. (28) retrospectively analyzed the efficacy and safety of modified FOLFOX6 regimen and DCF regimen as the first-line treatment for advanced gastric cancer, and it showed that the efficacy of modified FOLFOX6 was comparable to that of DCF regimen, while toxicity analysis showed that the adverse reactions of DCF in the blood system were significantly higher than that of modified FOLFOX6, however, as it was a retrospective analysis, the number of studies of the two regimens was quite different. Only the FOLFOX6 regimen was studied. Besides, it was unable to include all FOLFOXs regimen within the FOLFOX4 regimen, making it less precise in evidence-based medicine. In this study, through metaanalysis of 9 included studies, it showed that in the treatment of advanced gastric cancer, the efficacy of DCF regimen was similar to that of FOLFOXs regimen and the ORR and DCR were not statistically significant, but the adverse effects of the FOLFOXs regimen were significantly lower than that of the DCF regimen. This result can more comprehensively demonstrate the advantages and disadvantages of the clinical application of the two regimens. At present, the studies on long-term effects of chemotherapy for advanced gastric cancer such as surgical resection rate, disease-free survival, disease-bearing survival, 


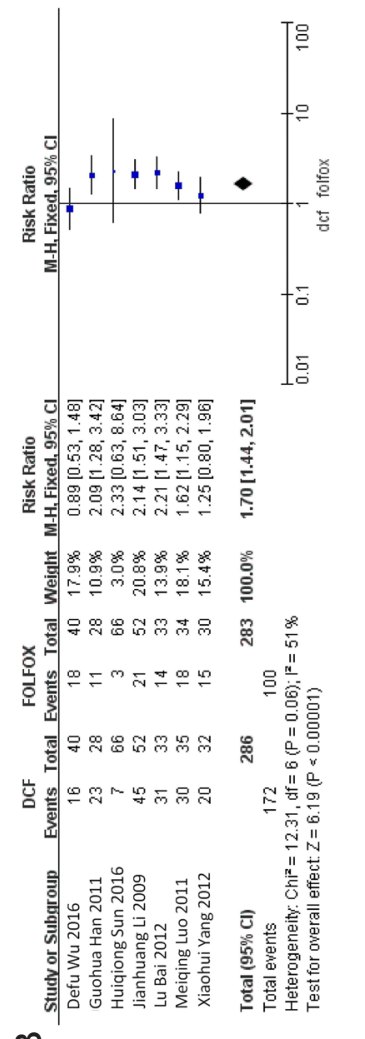

$\infty$

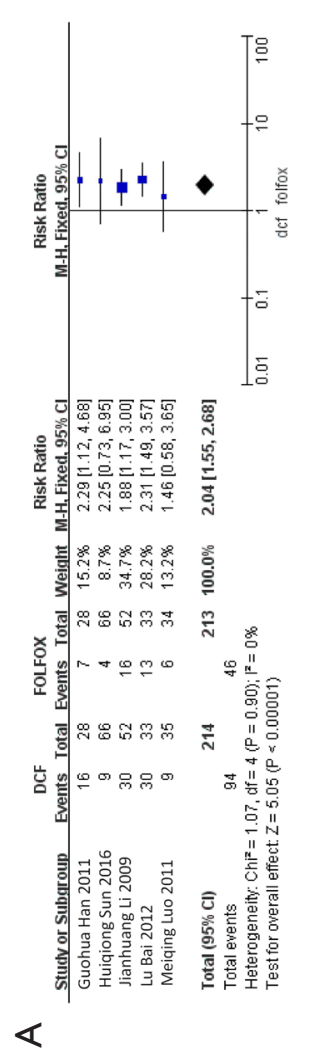

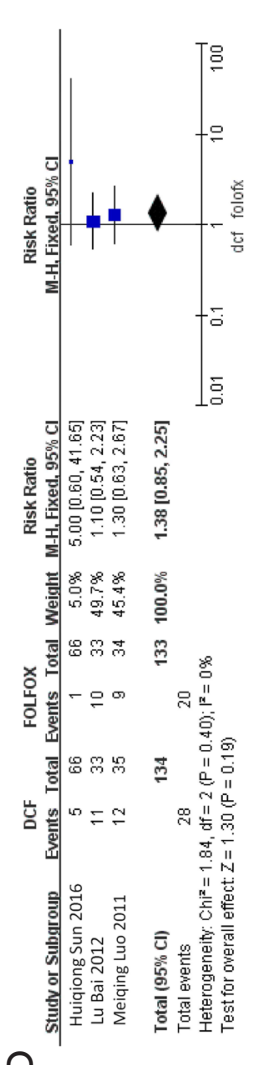

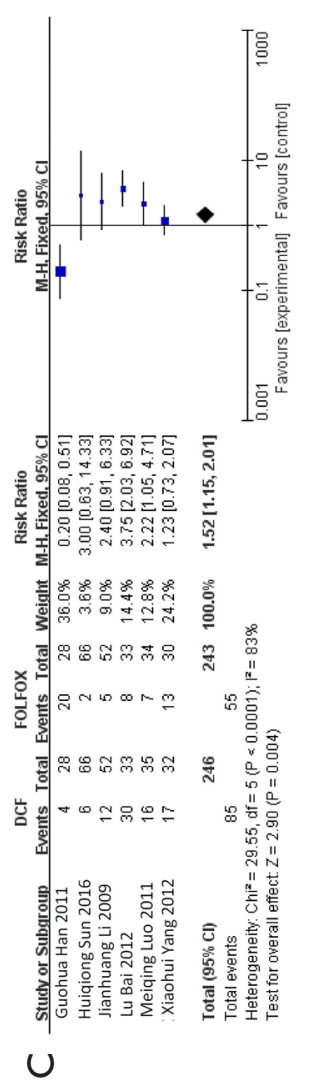

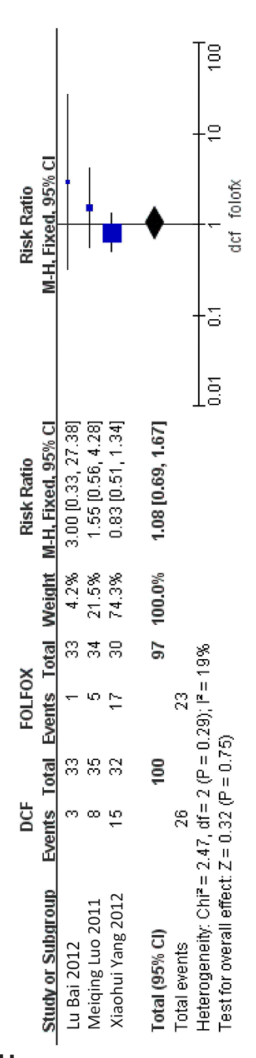

น

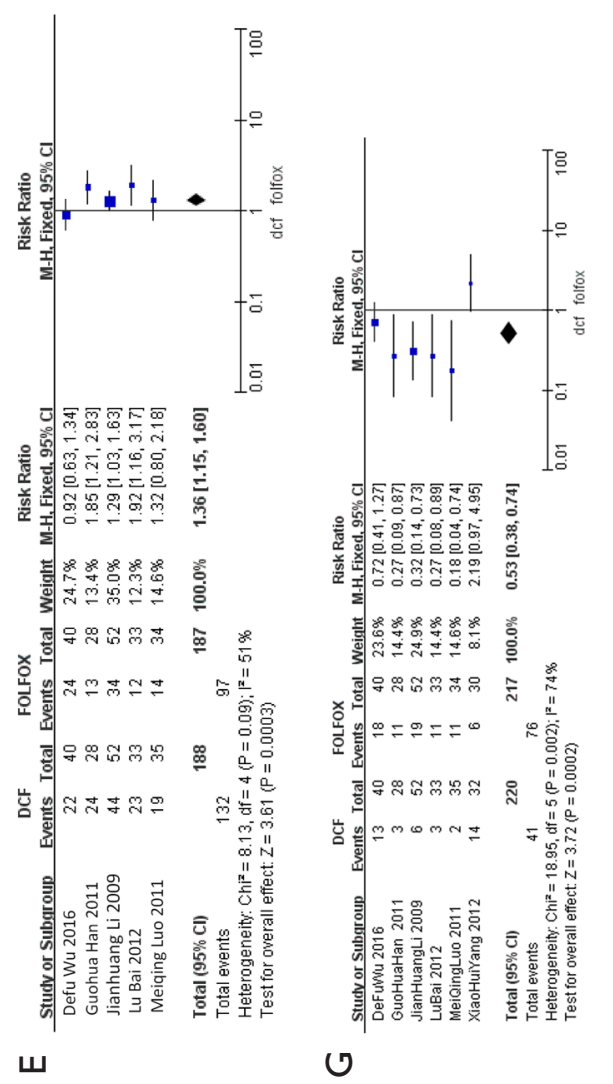

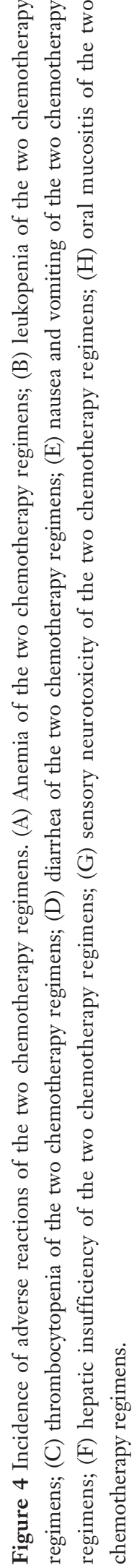


Table 4 Condition of the 7 included studies of FOLFOXs regimens grouping by different therapeutic doses

\begin{tabular}{|c|c|c|c|c|}
\hline Investigator & Grouping and treatment & $\begin{array}{c}\text { Number of } \\
\text { participants, N }\end{array}$ & $\mathrm{CR}+\mathrm{PR}$ & $\begin{array}{l}\text { Effective rate } \\
\text { (\%) }(\mathrm{CR}+\mathrm{PR}) / \mathrm{N}\end{array}$ \\
\hline $\begin{array}{l}\text { Meiqing Luo (3), } \\
\text { Guohua Han (4), } \\
\text { Jianhuang Li (8) }\end{array}$ & $\begin{array}{l}\text { Group I: L-OHP } 85 \mathrm{mg} / \mathrm{m}^{2}, \mathrm{~d} 1 \text {; LV } 200 \mathrm{mg} / \mathrm{m}^{2}, \mathrm{~d} 1-2, \mathrm{FU} 400 \mathrm{mg} / \mathrm{m}^{2} \\
\text { intravenous infusion, d1-2; followed by FU } 400 \mathrm{mg} / \mathrm{m}^{2} \text { intravenous } \\
\text { pump } 22 \mathrm{~h} \text {, d1-2; } 2 \text { courses of treatment }\end{array}$ & 114 & 64 & 56.14 \\
\hline $\begin{array}{l}\text { Lihua Fang (7), } \\
\text { Defu Wu (10) }\end{array}$ & $\begin{array}{l}\text { Group II: L-OHP } 85 \mathrm{mg} / \mathrm{m}^{2}, \mathrm{~d} 1 \text {; LV } 200 \mathrm{mg} / \mathrm{m}^{2}, \mathrm{~d} 1-2 ; \text { FU } 400 \mathrm{mg} / \mathrm{m}^{2} \\
\text { intravenous infusion, d1; followed by FU } 600 \mathrm{mg} / \mathrm{m}^{2} \text { intravenous pump } \\
22 \mathrm{~h} \text {, d1-2; } 3 \text { courses of treatment }\end{array}$ & 70 & 35 & 50.00 \\
\hline $\begin{array}{l}\text { Lu Bai (5), } \\
\text { Huiqiong Sun (6) }\end{array}$ & $\begin{array}{l}\text { Group III: L-OHP } 80-100 \mathrm{mg} / \mathrm{m}^{2}, \mathrm{~d} 1 \text {; LV } 200 \mathrm{mg} / \mathrm{m}^{2}, \mathrm{~d} 1 \text {; FU } 400 \mathrm{mg} / \mathrm{m}^{2} \text {, } \\
\text { d1; followed by } 2,400-3,000 \mathrm{mg} / \mathrm{m}^{2} 46 \mathrm{~h} ; 2 \text { courses of treatment }\end{array}$ & 99 & 44 & 44.44 \\
\hline
\end{tabular}

The other two studies were not suitable for statistical analysis due to large differences in treatment doses. $\chi^{2}=2.910, P=0.233$

and overall survival time was relatively scarce, thus it is impossible to make a more systematic and accurate analysis on the chemotherapy regimens. At the same time, as the 9 included studies did not give a more detailed description of TNM stage, thus it was impossible to perform a subgroup analysis based on the TNM staging of the patients between the two groups to provide a more individualized efficacy evaluation.

\section{Adverse reaction analysis}

The common adverse reactions of DCF and FOLFOXs regimens mainly include anemia, leukopenia, thrombocytopenia, and nausea and vomiting, but the overall incidence of adverse reactions of FOLFOXs was significantly lower than that of DCF. FOLFOXs regimen has significant advantages. The incidence of hepatorenal dysfunction and oral mucositis was not statistically significant, but the incidence of sensory neurotoxicity and diarrhea was significantly higher than that of DCF. This result suggested that in the clinical work of chemotherapy for patients with advanced gastric cancer, the FOLFOXs regimen should be used first. If the patient has sensory neurotoxicity and diarrhea symptoms, with no or mild other adverse reactions, it can be replaced with DCF regimen as appropriate.

For the low incidence of adverse reactions of the FOLFOXs regimen, further analysis of different treatment doses of the regimen was performed and it showed no significant differences in the effective rate among the three different cumulative treatment doses. With the increase of treatment doses, there were no significant differences in the incidence of diarrhea, hepatorenal dysfunction, and oral mucositis among the groups, but the statistical difference of the incidence of adverse reactions such as anemia, leukopenia, thrombocytopenia, and nausea and vomiting was large in each study, making it inconvenient to analyze. This provides us an idea to further study the relationship between the therapeutic doses, course of treatment and adverse reactions of the FOLFOXs regimen, and at the same time, the adverse reactions of different treatment doses, and clarify the relationship between them and the incidence of various adverse reactions, which is helpful to select a better therapeutic doses for patients with corresponding underlying diseases in clinical applications.

\section{Conclusions}

In conclusion, the results of this meta-analysis showed that the efficacy of FOLFOXs regimen was comparable to that of DCF regimen in the treatment of advanced gastric cancer, but the incidence of adverse reactions was significantly lower, and there was no difference in efficacy between different treatment doses. Due to the limitations in the study area and quality of the included studies, the conclusions of this study still need to be further verified by more large-scale clinical studies.

\section{Acknowledgments}

Funding: The study was supported by Gansu Health Industry Scientific Research Program (gswsky2017-36) and Lanzhou University Second Hospital Cuiying Science and Technology Innovation Program (CY2018-BJ10).

\section{Footnote}

Reporting Checklist: The authors have completed the 
PRISMA reporting checklist. Available at http://dx.doi. org/10.21037/tcr-19-2564.

Conflicts of Interest: All authors have completed the ICMJE uniform disclosure form (available at http://dx.doi. org/10.21037/tcr-19-2564). The authors have no conflicts of interest to declare.

Ethical Statement: The authors are accountable for all aspects of the work in ensuring that questions related to the accuracy or integrity of any part of the work are appropriately investigated and resolved.

Open Access Statement: This is an Open Access article distributed in accordance with the Creative Commons Attribution-NonCommercial-NoDerivs 4.0 International License (CC BY-NC-ND 4.0), which permits the noncommercial replication and distribution of the article with the strict proviso that no changes or edits are made and the original work is properly cited (including links to both the formal publication through the relevant DOI and the license). See: https://creativecommons.org/licenses/by-nc-nd/4.0/.

\section{References}

1. Bray F, Ferlay J, Soerjomataram I et al. Global cancer statistics 2018: GLOBOCAN estimates of incidence and mortality worldwide for 36 cancers in 185 countries. CA Cancer J Clin 2018;68:394-424.

2. Wang Z, Meng H, Jiao S. Clinical observation of DCF regimen and FOLFOX regimen in the treatment of advanced gastric cancer. Chin J Med 2009;44:47-8.

3. Luo M, Kang M, Liao L, et al. Comparison of the efficacy of DCF and FOLFOX4 in the first-line treatment of advanced gastric cancer. Canc Res Prev Treat 2011;38:591-3.

4. Han G, Wang L, Shang Y. Comparison of the efficacy of DCF and FOLFOX4 regimens in the treatment of advanced gastric cancer. J Guiyang Med Coll 2011;36:379-81.

5. Bai L, Li Q. Comparison of efficacy between FOLFOX6 regimen and DCF regimen in the treatment of advanced gastric cancer. Guangdong Med J 2012;33:2118-21.

6. Sun HQ, Xue LG, Chen KF. Comparative analysis of efficacy of FOLFOX6 regimen and DCF regimen in the treatment of advanced gastric cancer. China Foreign Med Treat 2016;25:96-7.

7. Fang LH, Yi YJ, Liu J. Study on the effect of DCF regimen and FOLFOX4 regimen in the treatment of patients with advanced gastric cancer. J Clin Med Literat 2017;4:1785-7.

8. Li J, Li B, Zhong M. The efficacy of different combined chemotherapy regimens for advanced gastric carcinoma. Chin J Clin Oncol 2009;36:205-7.

9. Yang X, Chen J, Hao P. Observation of the therapeutic effect of different chemotherapy regimens in post gastric cancer surgery. China Mod Med 2012;19:191-2.

10. Wu D, Zhang T. Exploration of the clinical efficacy of modified DCF regimen and FOLFOX 4 regimen in the treatment of advanced gastric cancer. For All Health (Late version) 2016;10:135-6.

11. Cunningham D, Allum WH, Stenning SP, et al. Perioperative chemotherapy versus surgery alone for resectable gastroesophageal cancer. $\mathrm{N}$ Engl J Med 2006;355:11-20.

12. Wagner AD, Unverzagt S, Grothe W, et al. Chemotherapy for advanced gastric cancer. Cochrane Database Syst Rev 2010;(3):CD004064.

13. Hong YS, Song SY, Lee SI, et al. A phase II trial of capecitabine in previously untreated patients with advanced and/or metastatic gastric cancer. Ann Oncol 2004;15:1344-7.

14. Boku N, Yamamoto S, Fukuda H, et al. Fluorouracil versus combination of irinotecan plus cisplatin versus $\mathrm{S}-1$ in metastatic gastric cancer: a randomised phase 3 study. Lancet Oncol 2009;10:1063-9.

15. Lee JL, Kang YK, Kang HJ et al. A randomised multicentre phase II trial of capecitabine vs S-1 as first-line treatment in elderly patients with metastatic or recurrent unresectable gastric cancer. Br J Cancer 2008;99:584-90.

16. Lee SJ, Cho SH, Yoon JY, et al. Phase II study of S-1 monotherapy in paclitaxel- and cisplatin-refractory gastric cancer. Cancer Chemother Pharmacol 2009;65:159-66.

17. Jeung HC, Rha SY, Shin SJ, et al. A phase II study of S-1 monotherapy administered for 2 weeks of a 3-week cycle in advanced gastric cancer patients with poor performance status. Br J Cancer 2007;97:458-63.

18. Yamada Y, Higuchi K, Nishikawa K, et al. Phase III study comparing oxaliplatin plus S-1 with cisplatin plus S-1 in chemotherapy-naive patients with advanced gastric cancer. Ann Oncol 2015;26:141-8.

19. Koizumi W, Kim YH, Fujii M, et al. Addition of docetaxel to S-1 without platinum prolongs survival of patients with advanced gastric cancer: a randomized study (START). J Cancer Res Clin Oncol 2014;140:319-28.

20. Smyth EC, Cunningham D. Epirubicin, cisplatin, and 
capecitabine versus fluorouracil, leucovorin, and irinotecan for esophagogastric cancer: the original and the rest. J Clin Oncol 2015;33:2409.

21. Li Q, Wen F, Zhou C, et al. Prospective randomized phase II study of FOLFIRI versus FOLFOX7 in advanced gastric adenocarcinoma: a Chinese Western Cooperative Gastrointestinal Oncology Group Study. Oncotarget 2017;8:97890-9.

22. Wang X. Observation of the short-term clinical efficacy and adverse reactions of XELOX chemotherapy in the treatment of elderly patients with advanced gastric cancer. Guide China Med 2018;16:115-6.

23. Sun Y, Wang D, Su S. Efficacy and safety of 89 patients with locally advanced gastric cancer treated with XELOX chemotherapy. J Med Forum 2018;39:111-3.

24. Hu Y, Song H, Bi Y. The clinical research of SOX regimen in the treatment of advanced gastric carcinoma. Proceedings of the abiding the rules of diagnosis and treatment, encourage clinical trials. Beijing, China, The 8th Chinese Symposium on Medical Oncology, CSMO),

Cite this article as: Chen M, Fan Y, Zhao Z, Nie Y, Ma F, Wang X, Wei Q, Wang Y, Kang B, Liu Y, Chen H, Wang C. The efficacy and adverse reactions of DCF and FOLFOXs regimens for patients with advanced gastric cancer in China: a meta-analysis. Transl Cancer Res 2020;9(7):4279-4289. doi: $10.21037 /$ tcr-19-2564
The 3rd Annual Meeting of Chinese Society for Clinical Oncologists (CACO), China Anti-Cancer Association Clinical Chemotherapy of Cancer Professional Committee 2014 Academic Annual Meeting, 2014.

25. Bi X. Compare modified DCF regimen versus SOX regimen of efficacy and safety as first-time treatment for advanced gastric cancer. Dalian: Medical University, 2016.

26. Ding L. Comparison of the clinical efficacy and safety of SOX and XELOX in advanced gastric Cancer. Soochow: Soochow University, 2018.

27. Zaanan A, Samalin E, Aparicio T, et al. Phase III randomized trial comparing 5-fluorouracil and oxaliplatin with or without docetaxel in first-line advanced gastric cancer chemotherapy (GASTFOX study). Dig Liver Dis 2018;50:408-10.

28. Hacibekiroglu I, Kodaz H, Erdogan B, et al. Comparative analysis of the efficacy and safety of modified FOLFOX-6 and DCF regimens as first-line treatment in advanced gastric cancer. Mol Clin Oncol 2015;3:1160-4. 